\title{
Effects of Land Cover Patterns on Land Surface Temperatures Associated with Land Use Types along Urbanization Gradients in Shanghai, China
}

\author{
Zhigang Li ${ }^{1}$, Changkun Xie ${ }^{1}$, Dan Chen ${ }^{1}$, Hongyu Lu², Shengquan Che ${ }^{*}$ \\ ${ }^{1}$ Eco-Planning and Design Lab, School of Agriculture and Biology, Shanghai Jiao Tong University, Shanghai, China \\ ${ }^{2}$ International Education College, Zhengzhou University of Light Industry, Zhengzhou, China
}

Received: 29 May 2018

Accepted: 25 November 2018

\begin{abstract}
Rapid urbanization has led to increased land surface temperature (LST) and severe urban heat islands (UHIs). The impacts of land use/land cover (LULC) on LST have been extensively studied. However, the differences between land use and land cover and their implications in an urban environment are often overlooked. Taking the example of Shanghai in China, this study aimed to study the effects from land use types and land cover patterns on LST along urbanization gradients. The LST and LULC data of the study area were obtained from a Landsat ETM+ image and Map world Shanghai, respectively. Then, landscape metrics were selected and calculated for analyzing the land cover patterns. Correlation analysis and regression analysis were undertaken to determine the relationship between LST and land cover patterns at the land use level. The results showed that it was inadequate to treat land cover as the single factor affecting LST. Furthermore, LST values did not simply decrease along the urbanization gradients at the land use level. Even though land cover patterns significantly affected LST, land cover variables related to LST varied greatly among the various land use types. The findings in our study provide additional knowledge for optimizing land cover patterns associated with different land use types, which may mitigate the adverse impacts of UHIs at a fine scale.
\end{abstract}

Keywords: urban heat island, landscape metrics, urbanization, sustainability, land use management

\section{Introduction}

Rapid urbanization driven by population growth and economic development has led to drastic and widespread changes to the Earth's surface, causing the replacement of natural surfaces such as vegetation with impervious surface materials such as concrete,

*e-mail: chsq@sjtu.edu.cn asphalt and buildings [1-4]. The widespread land use/ land cover (LULC) transformations have brought about both ecological and environmental problems at multiple scales [5-7]. Impervious surfaces could absorb and emit more thermal energy when compared with natural areas due to greater absorption of solar radiation, resulting in the creation of urban heat islands (UHIs), which have become one of the most severe issues resulting from LULC transformation [8-10]. Many studies have been carried out on heat islands around the world and 
confirmed that the UHI effect has a detrimental impact on sustainable development and public health [11-13]. Higher temperatures in urban areas could increase the demands for air conditioning and reduce indoor and outdoor comfort [14]. Furthermore, heat stress increases the probability of endemic diseases, respiratory illnesses, and cardiovascular mortality of residents in urban areas [15]. As population concentration in urban areas is continuously growing across the world,particularly in developing countries, over half of the world's population may be unavoidably affected by the UHI effect [12, $16,17]$. Therefore, better understanding of the driving forces of the UHI effect is critical for sustainable urban development.

Traditionally, UHIs can be evaluated with air temperature measurement in the urban canopy layer. On the other hand, UHIs can be characterised by surface urban heat islands, which refer to land surface temperature (LST) [18, 19]. Air temperature is generally determined in situ and the data over large spatialtemporal scales are still limited, while LST can be obtained and calculated with powerful remote sensing technology, even on multiple scales. Recently, several algorithms have been developed for LST retrieval based on remotely sensed thermal sensors [20, 21]. LST has been an indicator for surface energy balance [22], which is sensitive to surface indicators such as land cover and land use [19,23], while the relations of LST with LULC were rarely studied by distinguishing the differences between land use and land cover. Notably, these two surface indicators and their discrepant impacts on the urban thermal environment are sometimes confused and not clearly distinguished. Specifically, land cover refers to the biophysical patterns of the land surface, while land use refers to the use of the land according to socio-economic functions [19]. By distinguishing between these two surface indicators, the linkage between biophysical features such as land cover and anthropogenic features such as socio-economic activities can be revealed [24].

Under constant meteorological conditions, the relationship between LST and land cover has been extensively studied on multiple scales [25-28]. Land cover data include land cover compositions and configuration patterns. For land cover compositions, the surface characteristics of different land cover components such as albedo and evapotranspiration can have discrepant effects on the LST [5, 29]. And most studies illustrate that the vegetated land is associated with cooling effects while built-up land is relevant to uplifted LST [21, 29]. In addition to the land cover compositions, a range of landscape metrics with different meanings have been developed, which could help better understand the spatial patterns of land cover and their relations with ecological processes [30, 31]. These landscape metrics have significant effects on LST because the heat exchange among adjacent land cover patches can be influenced by their spatial patterns [29, 32]. In the past few decades, a large number of landscape metrics have been widely used to characterize the land cover configuration patterns and to quantify their effects on LST distribution [5, 29, 33, 34], while the relationship between LST and land cover configuration patterns have been found to be inconsistent or contradictory in some previous studies[25-27], which was mostly explained by the scale effect or regional variations [25, 26, 29].

On the other hand, anthropogenic heat discharge dueto energy consumption and human metabolism in various land uses was quite different, which could also make considerable impacts on the LST [35-37]. Furthermore, land coverin various land uses might be quite different due to their special social-economic functions. Therefore, it is inadequate to simply treat land cover as the single driving factor of LST distribution. However, only a few studies have been conducted to explore the discrepant impacts of land use and land cover on LST [19]. Whether or not the relations of LST with land cover would be changed in various land use types with different anthropogenic activities has been rarely documented. Therefore, more comprehensive studies on the relations of LST with land cover by both considering various land use types and urbanization gradients are quite necessary[38], which could provide insights regarding urban thermal environment mitigation at a fine scale.

In this study, the southwestern transect of Shanghai was selected as the research region, which is one of the main development axes experiencing rapid urbanization in this metropolitan city [39]. The specific objectives of this study were as follows: (1) to characterize and quantify the LST variations among various land use types along urbanization gradients; (2) to investigate whether there are different relationships of LST with land cover in various land use types; and (3) to analyze the optimized land cover patterns for mitigating urban thermal environment at a fine scale. More understanding of the factors that affect LST in terms of land use and land cover can help urban land developers and planners regulate urban land planning as well as manage the urban thermal environment, especially in some quick developing areas.

\section{Material and Methods}

\section{Study Area}

Shanghai, $30^{\circ} 82^{\prime} 30^{\prime \prime}-31^{\circ} 82^{\prime} 70^{\prime \prime} \mathrm{N}$ and $120^{\circ} 85^{\prime} 20^{\prime \prime}-$ $121^{\circ} 84^{\prime} 50^{\prime \prime} \mathrm{E}$, is considered one of the largest and most important industrial centers in the world, and has a subtropical monsoon climate. According to data from the Meteorological Bureau of Shanghai, the monthly mean air temperature ranges from $4^{\circ} \mathrm{C}$ to $28^{\circ} \mathrm{C}$ (data calculated from observations from 1951 to 2016). The total area of Shanghai is $6340.5 \mathrm{~km}^{2}$ with a population of 23.8 million. The urbanization of Shanghai has been rapid since the implementation of the "Reform and Open Policy" in 1978. An increase in the built-up 


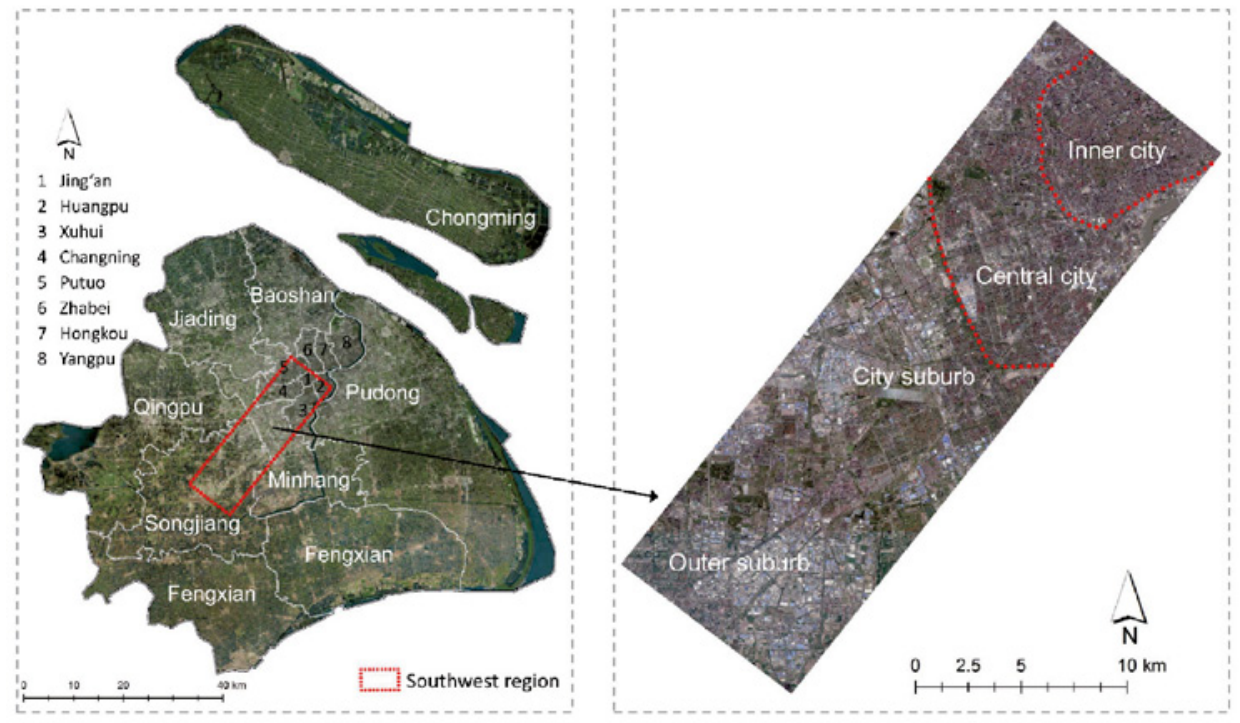

Fig. 1. Location of the southwest region in Shanghai, China (data source: MAP WORLD 2013_http://www.tianditu.com/).

area has been reported in Shanghai, which went from $1073 \mathrm{~km}^{2}$ in 1998 to $2408 \mathrm{~km}^{2}$ in 2011 (Shanghai Municipal Statistics Bureau, 2013). The study area selected in this paper was primarily located within the southwest region of Shanghai (Fig. 1). According to the development history of Shanghai, it was one of the major development axes of this city and has experienced rapid urbanization (Shanghai Municipal Statistics Bureau, 2013). Along this development axis, land use types constructed in different eras can be found. In the last 20 years, many residential, industrial areas have been constructed along this axis and it is representative of the development history of Shanghai.

\section{Definitions of Urbanization Gradients and Land Use/Land Cover Classification}

In this study, urbanization gradients were defined based on the urban development process in Shanghai, including the inner city, central city, city suburb, and outer suburb (Fig. 1). The inner city is located within the inner ring road of Shanghai, which comprises

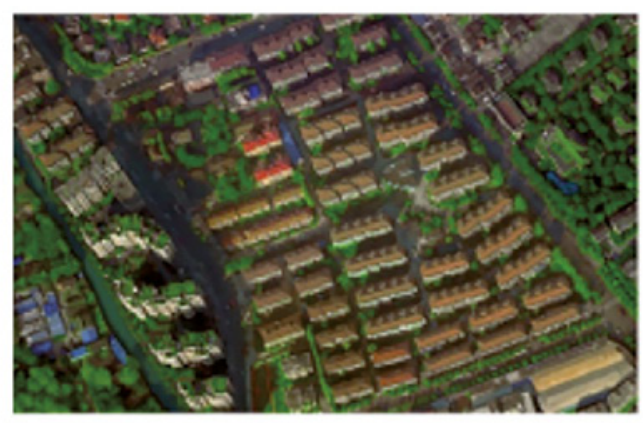

Residential land use

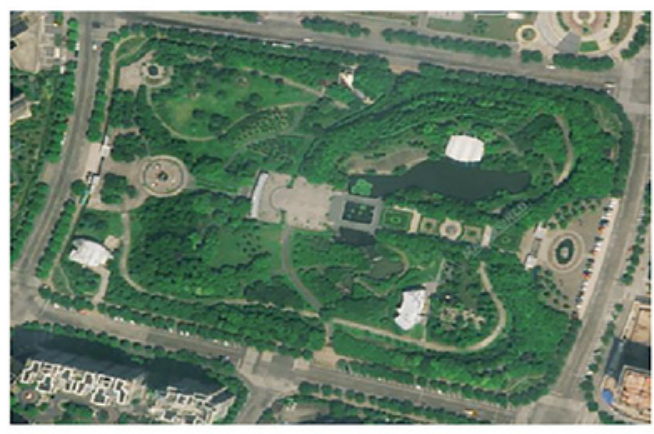

Park land use

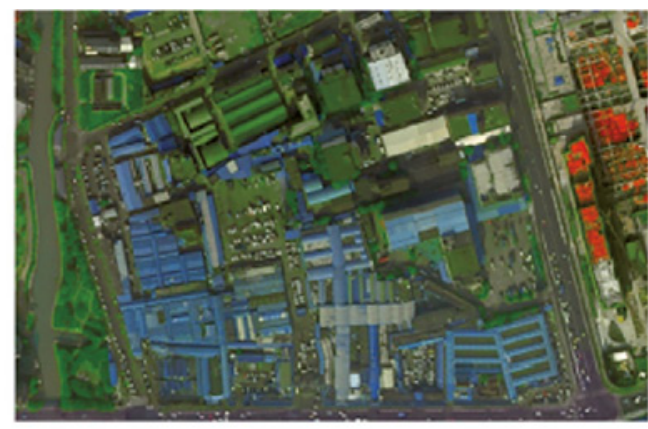

Industrial land use

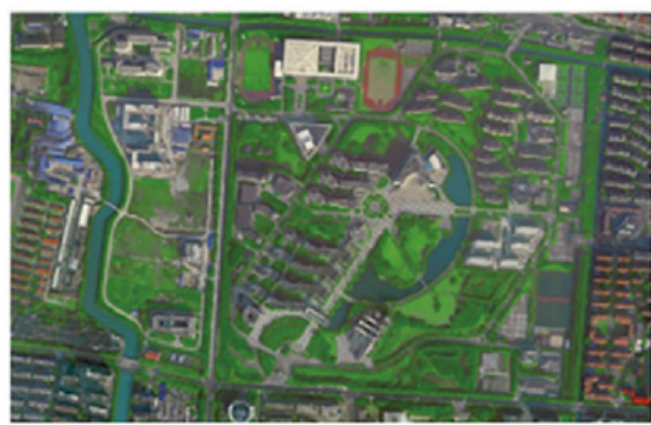

Institutional land use

Fig. 2. Google Earth image showing the four urban land use types. 
Table 1. Identified polygons per land use type in the study area.

\begin{tabular}{|c|c|c|c|c|}
\hline $\begin{array}{l}\text { Types of land } \\
\text { use }\end{array}$ & Description & $\begin{array}{c}\text { Locations of } \\
\text { polygons }\end{array}$ & No. of polygons & $\begin{array}{l}\text { Total area } \\
\text { (ha) }\end{array}$ \\
\hline \multirow{4}{*}{$\begin{array}{l}\text { Residential land } \\
\text { use }\end{array}$} & \multirow{4}{*}{$\begin{array}{l}\text { Lands for private residences or dwellings; the boundaries } \\
\text { of these residential areas were clear }\end{array}$} & Inner city & 18 & 80.7 \\
\hline & & Central city & 22 & 140.3 \\
\hline & & City suburb & 14 & 71.3 \\
\hline & & Outer suburb & 14 & 68.4 \\
\hline \multirow{4}{*}{$\begin{array}{l}\text { Industrial land } \\
\text { use }\end{array}$} & \multirow{4}{*}{$\begin{array}{l}\text { Lands for industrial purposes, generally with multiple } \\
\text { buildings for various industrial activities, such as workspaces, } \\
\text { factories or warehouses }\end{array}$} & Inner city & 0 & 0 \\
\hline & & Central city & 12 & 91.9 \\
\hline & & City suburb & 10 & 138.6 \\
\hline & & Outer suburb & 12 & 266.1 \\
\hline \multirow{4}{*}{ Park land use } & \multirow{4}{*}{$\begin{array}{l}\text { Lands for public recreation, with the functions such as } \\
\text { ecology, beautification and emergency shelters }\end{array}$} & Inner city & 3 & 41.9 \\
\hline & & Central city & 5 & 69.8 \\
\hline & & City suburb & 4 & 55.9 \\
\hline & & Outer suburb & 4 & 61.4 \\
\hline \multirow{4}{*}{$\begin{array}{l}\text { Institutional } \\
\text { land use }\end{array}$} & \multirow{4}{*}{$\begin{array}{l}\text { Lands for colleges, universities, research institutions and the } \\
\text { associated infrastructure }\end{array}$} & Inner city & 3 & 122.4 \\
\hline & & Central city & 4 & 163.9 \\
\hline & & City suburb & 0 & 0 \\
\hline & & Outer suburb & 0 & 0 \\
\hline
\end{tabular}

development ranging in age from 20 years to well over 100 years,and includes a mix of the new and the old. The central city contains the areas within the outer ring road with the exception of the inner city, which has been developed for more than 15 years and has less history than that of the inner city. The city suburbs include the areas surrounding the central city, which have been developed for 10-20 years; and the outer suburbs are satellite areas far from the central city, which have been developed for less than 10 years (Overall Planning of Shanghai (1999-2020)).

As mentioned above, land use and land cover have quite different meanings in urban ecosystems. Land use classification was obtained to represent different socioeconomic activities based on their ecological effects and the existing national standards for land use classification (GB50137-2011). Four dominant land use types with clear boundaries along the urbanization gradients were identified in this study: residential, industrial, parks, and institutional land use (Fig. 2, Table 1). Based on previous studies, in each land use polygon, four land cover types were defined according to their biophysical characteristics, including vegetated land cover, building land cover, roads and squares, and water bodies [40].

\section{Land Use and Land Cover Data Collection}

The land use polygons and land cover features were characterized using Map world Shanghai data with a spatial resolution of $0.5 \mathrm{~m}$, which were obtained from the Shanghai Institute of Surveying and Mapping. First, all images were geometrically corrected to a topographic scale of 1:10,000 with a first-order polynomial model and nearest neighbor algorithm. Second, four land use types with clear boundaries were allocated along the urbanization gradients by integrating the Map world data and the cadaster map of Shanghai. Extensive field survey and manual editing were conducted to correct these selected polygons. The selected land use polygons are representative of the land use types (Table 1). For each land use type, the identified land use polygons should have a consistent surrounding environment without an obvious cooling or heat source. For each land use polygon, the land cover was further classified by visual interpretation according to the Mapworld data of Shanghai. A field survey was also conducted to ensure the accuracy of the visual interpretation. Fig. 3 shows one example of a land cover map of residential land use.

\section{Land Surface Temperature Retrieval}

In this study, the Landsat ETM+ image was acquired from Geospatial Data Cloud in China on July 20, 2013, which was a day with clear atmospheric conditions and so was conducive to obtain an obvious UHI scenario. The image data was first processed by using the multiimage local adaptive regression analysis model in the Geospatial Data Cloud to overcome the SLC-off striping problem of Landsat ETM+ images since 2003. Then, LST was estimated through the generalized singlechannel method [41] based on the infrared thermal band of Landsat ETM+.The main steps for estimating 


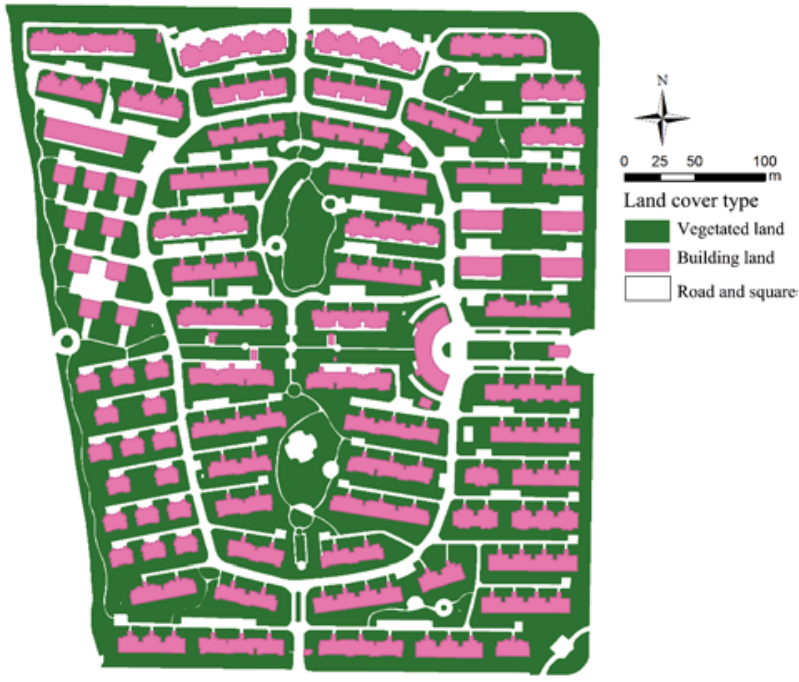

Fig. 3. One example map showing land cover data within residential land use.

LST include: (1) image pre-processingfor correcting the radiometric and geometrical distortions; (2) converting the calibrated digital output to absolute units of atsensor spectral radiance; (3) transformation of spectral radiance to brightness temperature; (4) calculating the land surface temperature based on the brightness temperature and the spectral emissivity data from different land cover types [5, 42, 43].

All the above steps for LST retrieval were performed with the help of ENVI 5.0 software. Based on the generated LST map (Fig. 4) and identified land use polygons in Section "Land Use and Land Cover Data Collection", the LST value in each land use polygon could be calculated via zonal statistical analysis by ArcGIS 10.2.

\section{Land Cover Patterns Calculation}

In this study, the land cover compositions and configurations in land use polygons were analyzed with the most important and generally applied landscape metrics. The percentage of each land cover (PLAND) was involved to describe the land cover compositions in each land use polygon [44]. The configurations of land cover were characterized and the size, shape, and fragmentation characteristics of the land cover patches were analyzed, which were free from colinearity. Six landscape metrics were selected, including patch density (PD), mean patch size (MPS), patch size coefficient of variance (PSCoV), mean shape index (MSI), mean nearest neighbor (MNN), and mean proximity index (MPI). Table 2 shows the detailed formulas and descriptions of these selected landscape matrices. For these metrics, MPS and PSCoV were applied to describe the patch size of the land cover patches; MSI was applied to describe the patch shape of land cover patches; and PD, MPI, and MNN were applied to describe the fragmentation characteristics of the land

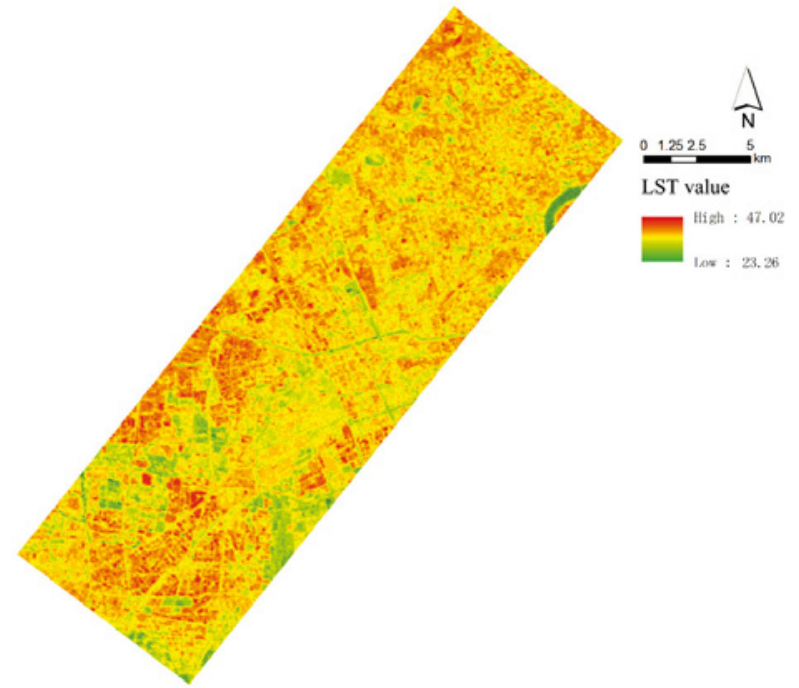

Fig. 4. Land surface temperature (LST) distribution in the study area of Shanghai on July 20, 2013.

cover patches. The landscape metrics were computed with FRAGSTATS [44].

Finally, each land use polygon ID was associated with the LST values and all land cover pattern values. The data were gathered and a database created for further statistical analysis.

\section{Statistical Analysis}

The statistical analysis in this study was performed as per the following steps. First, a descriptive analysis was conducted to summarize the general features of land cover compositions in different land use types. Second, the average LST value of each land use was calculated. After the above two steps, the average land cover compositions and average LST of each land use type were obtained. Next, one-way analysis of variance (ANOVA) was applied to investigate whether there was significant difference for LST and land cover compositions in different land use types along urbanization gradients $(p<0.05)$. Since all institutional land use samples in this study area were only located in the inner city and central city (Table 1), the independentsamples $T$ test was performed for this land use type in the urbanization gradients analysis.

The relationship between LST and land cover patterns in various land use types was first tested using Pearson's correlation analysis. As the configuration variables of land cover are related to land cover composition significantly, partial correlation analysis was further conducted by controlling the variable of land cover composition. These correlation analyses were conducted with a statistical significance of $p<0.05$. In some land use types where the LST was significantly changed along urbanization gradients, the relationship between land cover patterns and LST was also tested with Pearson's and partial correlation analysis. Based 
Table 2. Descriptions and formulas of the selected landscape metrics.

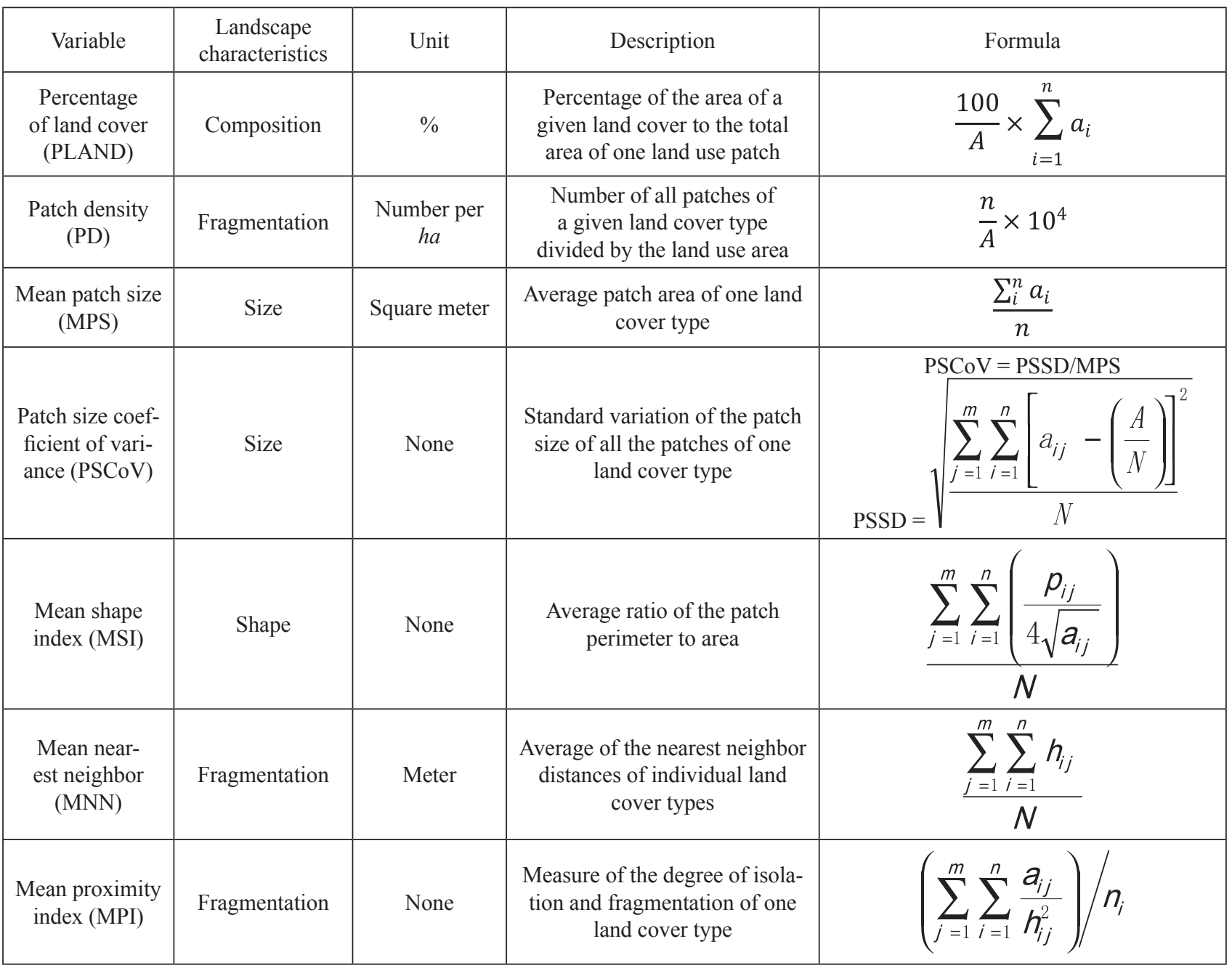

PSSD: patch size standard deviation; A: total landscape area $\left(\mathrm{m}^{2}\right) ; \mathrm{a}_{\mathrm{ij}}$ : area $\left(\mathrm{m}^{2}\right)$ of patch $(\mathrm{i}, \mathrm{j}) ; \mathrm{n}$ : number of land cover patches; $\mathrm{m}$ : number of patches of one given land use type; $p_{\mathrm{ij}}$ : perimeter $(\mathrm{m})$ of patch $(\mathrm{i}, \mathrm{j}) ; \mathrm{h}_{\mathrm{ij}}$ : shortest distance to patch $(\mathrm{i}, \mathrm{j})$.

on the above-mentioned correlation analysis, traditional multiple ordinary least squares (OLS) regression was then used to create the LST models. The dependent variable for this regression analysis was the mean LST in each sampled land use polygon. The independent variables were the landscape metrics listed in Table 2. The final selection of the independent variables in specified models were identified by a forward selection in SPSS. All the above statistics were performed with the SPSS software package (SPSS Inc. v18.0).

\section{Results and Discussion}

\section{LST Variations among Different Land Use Types and their Related Factors}

The mean LST values in the selected four land use types were provided in Table 3, which were significantly different $(p<0.05)$. The mean LST value was highest in the industrial land use $\left(37.48^{\circ} \mathrm{C}\right)$, followed by institutional $\left(36.73^{\circ} \mathrm{C}\right)$, residential $\left(36.59^{\circ} \mathrm{C}\right)$, and park $\left(35.19^{\circ} \mathrm{C}\right)$ land use. Furthermore, it was found that the mean LST values were not significantly different for residential and institutional land use, and even the land cover compositions were quite different between these two land use types, while the mean LST values were significantly different for industrial and institutional land uses with similar land cover compositions (Table 3). These findings indicate that LST distributions were inconsistent with the land cover at the land use level $[19,26]$. Land cover should not be considered the single most effective factor of LST. According to some previous studies, the effects from land cover on LST could be considerably mediated by human activities such as human metabolism, buildings, and traffic emissions in various land use types [35-37]. The dense populations in residential and institutional land uses could also influence the LST distribution by anthropogenic heat discharge such as building energy use (including lighting and air conditioning), human metabolism, and other activities [36, 37]. Additionally, for industrial land use, considerable amounts of sensible and latent heat are released due to the consumption of energy for 
Table 3. Mean LST and land cover compositions of different land use types in the study area.

\begin{tabular}{|c|c|c|c|c|}
\hline & Residential land use & Industrial land use & Park land use & Institutional land use \\
\hline Mean LST $\left({ }^{\circ} \mathrm{C}\right)$ & $36.59 \mathrm{a}$ & $37.48 \mathrm{~b}$ & $35.19 \mathrm{c}$ & $36.73 \mathrm{a}$ \\
\hline Vegetated land cover (\%) & $33.12 \mathrm{a}$ & $21.75 \mathrm{~b}$ & $57.61 \mathrm{c}$ & $27.75 \mathrm{~b}$ \\
\hline Building land cover (\%) & $31.05 \mathrm{a}$ & $33.74 \mathrm{a}$ & $1.61 \mathrm{~b}$ & $24.04 \mathrm{c}$ \\
\hline Roads and squares (\%) & $33.34 \mathrm{a}$ & $42.84 \mathrm{~b}$ & $25.09 \mathrm{c}$ & $45.90 \mathrm{~b}$ \\
\hline Water bodies (\%) & $2.44 \mathrm{a}$ & $1.74 \mathrm{a}$ & $15.76 \mathrm{~b}$ & $2.61 \mathrm{a}$ \\
\hline
\end{tabular}

Different letters in the same row represent significantly different values based on the Duncan's test $(p<0.05)$.

Table 4. Partial correlation between LST and land cover patterns in different land use types.

\begin{tabular}{|c|c|c|c|c|}
\hline & Residential land use & Industrial land use & Park land use & Institutional land use \\
\hline \multicolumn{5}{|c|}{ Vegetated land cover } \\
\hline Percentage of land cover (PLAND) & $-0.605^{* *}$ & $-0.459 * *$ & & \\
\hline Patch density (PD) & $-0.310^{*}$ & $-0.454 * *$ & & \\
\hline \multicolumn{5}{|l|}{ Mean patch size (MPS) } \\
\hline \multicolumn{5}{|l|}{ Mean proximity index (MPI) } \\
\hline Mean nearest neighbor (MNN) & $0.376^{* *}$ & & & $0.903^{*}$ \\
\hline $\begin{array}{c}\text { Patch size coefficient of variance } \\
\text { (PSCoV) }\end{array}$ & $-0.414 * *$ & & & \\
\hline Mean shape index (MSI) & & & $-0.799 *$ & \\
\hline \multicolumn{5}{|c|}{ Building land cover } \\
\hline $\begin{array}{l}\text { Percentage of land cover } \\
\text { (PLAND) }\end{array}$ & $0.672 * *$ & $0.613 * *$ & & \\
\hline Patch density (PD) & $0.452 * *$ & & & \\
\hline Mean patch size (MPS) & $-0.303 * *$ & $0.329 *$ & & $0.971^{*}$ \\
\hline Mean proximity index (MPI) & $0.600 * *$ & & & \\
\hline Mean nearest neighbor (MNN) & $-0.744 * *$ & & & \\
\hline \multicolumn{5}{|l|}{$\begin{array}{l}\text { Patch size coefficient of variance } \\
\text { (PSCoV) }\end{array}$} \\
\hline Mean shape index (MSI) & & & $-0.858 *$ & \\
\hline \multicolumn{5}{|c|}{ Roads and squares } \\
\hline \multicolumn{5}{|l|}{$\begin{array}{l}\text { Percentage of land cover } \\
\text { (PLAND) }\end{array}$} \\
\hline \multicolumn{5}{|l|}{ Patch density (PD) } \\
\hline \multicolumn{5}{|l|}{ Mean patch size (MPS) } \\
\hline Mean proximity index (MPI) & & $0.344 *$ & & \\
\hline \multicolumn{5}{|l|}{ Mean nearest neighbor (MNN) } \\
\hline \multicolumn{5}{|l|}{$\begin{array}{l}\text { Patch size coefficient of variance } \\
\text { (PSCoV) }\end{array}$} \\
\hline Mean shape index (MSI) & & & & \\
\hline
\end{tabular}

* Correlation was significant at the level of 0.05 (two-tailed)

** Correlation was significant at the level of 0.01 (two-tailed) 
Table 5. Results from the regression models for the LST in different land use types.

\begin{tabular}{|c|c|c|c|c|c|c|}
\hline Land use & Model & Variables & Coefficient & Stand. Coeff. & Model R² & Adjusted $\mathrm{R}^{2}$ \\
\hline All & 1 & $\begin{array}{c}\text { Build_PLAND } \\
\text { Veg_PLAND } \\
\text { Veg_PD } \\
\text { Build_MPS }\end{array}$ & $\begin{array}{c}2.444 * * \\
-0.954 * * \\
-0.024 * * \\
0.000 * * \\
\end{array}$ & $\begin{array}{c}0.530 \\
-0.214 \\
-0.241 \\
0.178 \\
\end{array}$ & 0.614 & 0.621 \\
\hline Residential & 2 & $\begin{array}{c}\text { Build_MNN } \\
\text { Veg_PLAND } \\
\text { Veg_PD } \\
\text { Build_PSCoV }\end{array}$ & $\begin{array}{l}-0.069 * * \\
-1.463 * * \\
-0.018^{* *} \\
-0.003 *\end{array}$ & $\begin{array}{l}-0.541 \\
-0.398 \\
-0.253 \\
-0.168\end{array}$ & 0.682 & 0.662 \\
\hline Industrial & 3 & $\begin{array}{c}\text { Build_PLAND } \\
\text { Veg_PD } \\
\text { Veg_MPS }\end{array}$ & $\begin{array}{c}1.381 * * \\
-0.076 * * \\
0.000 * *\end{array}$ & $\begin{array}{c}0.473 \\
-0.573 \\
-0.402 \\
\end{array}$ & 0.623 & 0.587 \\
\hline Park & 4 & $\begin{array}{c}\text { Build_MSI } \\
\text { Veg_PD }\end{array}$ & $\begin{array}{c}-0.956^{* *} \\
0.019 *\end{array}$ & $\begin{array}{c}-0.770 \\
0.445\end{array}$ & 0.737 & 0.684 \\
\hline
\end{tabular}

Build_PLAND and Veg_PLAND refer to the percentage of building land cover, vegetated land cover, respectively.

Build_MPS, Build_MNN, Build_PSCoV, Build_MSI refer to the mean patch size, mean nearest neighbor, patch size coefficient of variance and mean shape index of building land cover, respectively. Veg_PD and Veg_MPS refer to the patch density and mean patch size of vegetated land cover, respectively.

* Correlation was significant at the level of 0.05 (two-tailed)

** Correlation was significant at the level of 0.01 (two-tailed)

industrial production [37]. Combined with the relatively low percentage of vegetated land cover $(21.75 \%)$ and high percentage of building land cover $(33.74 \%)$, this consumption-emission process contributed to the highest LST value in residential land use compared with institutional land use.

According to the statistical results in Tables 4 and 5 , the mean LST values were significantly related to the land cover patterns, especially for vegetated and building land cover. The land cover compositions showed a stronger effect on LST than land cover configurations, which was consistent with some previous studies $[19,25$, $45,46]$. Liu et al. found that the biophysical factors of land cover were most important to explain LST variation [46]. Moreover, it was also found that the relationship between LST and land cover patterns differed greatly among the four land use types. For instance, the PLAND of vegetated and building land had significant

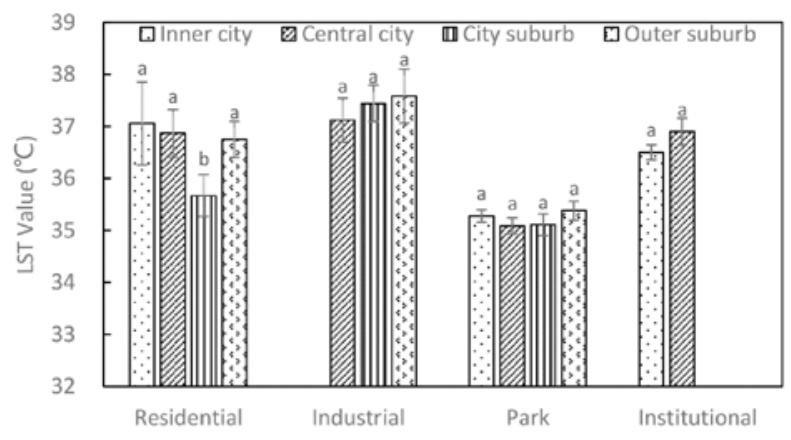

Fig. 5. LST values in each land use type along urbanization gradients; different letters represent significantly different LST values based on Duncan's test $(p<0.05)$. effects on LST for the residential and industrial land use, but no correlations were found for that of park and institutional land use. In residential land use, the LST was significantly affected by more variables of land cover when compared to the other three land use types. Interestingly, the relationships between the LST and MPS of building land was inconsistent for residential $\left(-0.303^{* *}\right)$, industrial $\left(0.329^{*}\right)$, and institutional $\left(0.971^{*}\right)$ land use types. Furthermore, the correlation between the LST and Veg_PDwas not consistent for the residential $\left(-0.018^{* *}\right)$, industrial $\left(-0.076^{* *}\right)$, and park $\left(0.019^{*}\right)$ land use types. These findings further reveal the complicated mechanism of LST distribution at a fine scale. The relationships of LST with land cover would not always be consistent in various land use types. The different anthropogenic activities and socio-economic functions in various land use types may influence the effects of land cover on LST values [19].

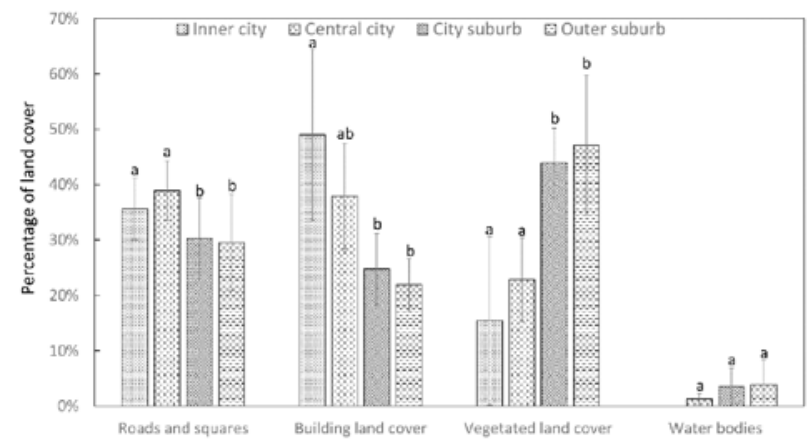

Fig. 6. Land cover compositions of residential land use along urbanization gradients; different letters represent significantly different land cover percentages based on Duncan's test $(p<0.05)$. 

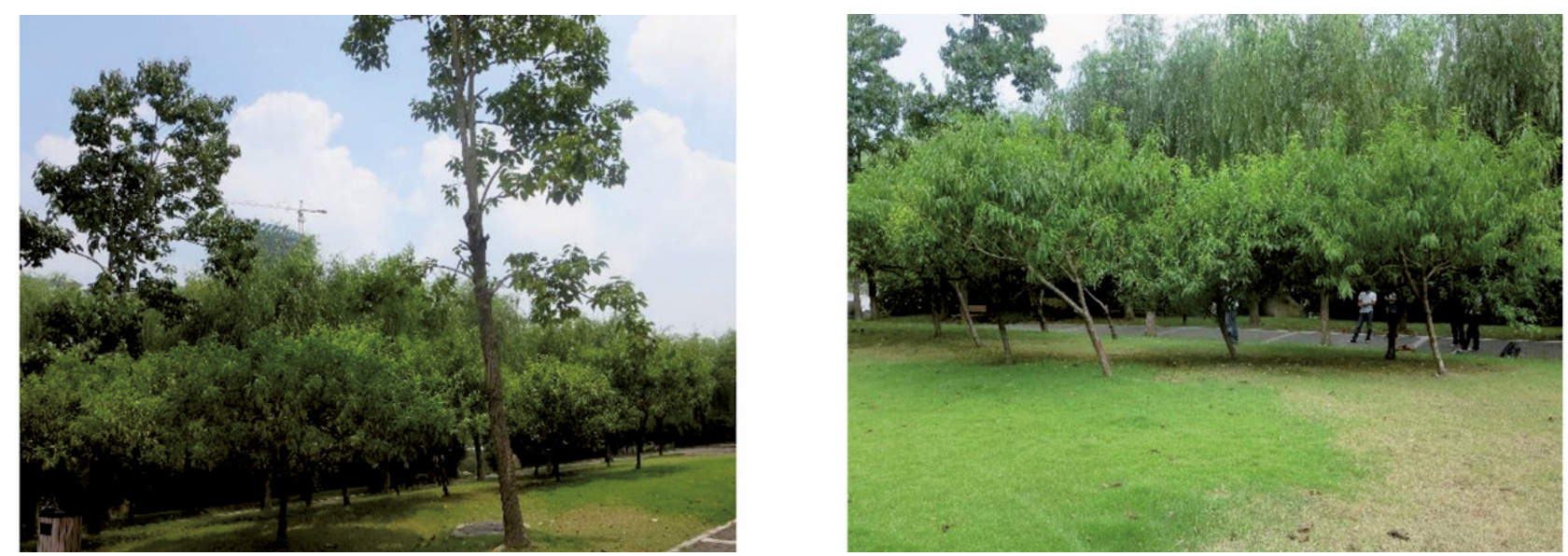

Fig. 7. Vegetated land in residential land use samples of the outer suburbs.

\section{LST Variations Along Urbanization Gradients at Land Use Level and their Related Factors}

Even though many previous studies have confirmed that urban areas have higher surface temperatures than their rural surroundings [38, 47], it was found in this study that LST values were not simply decreased along urbanization gradients at the land use level. A significant LST variation was only observed in residential land use along urbanization gradients (Fig. 5). This finding was consistent with the report from Buyantuyev et al. stating that although the urban core was generally warmer than the rest of the area, no consistent trends were found along the urbanization gradient at the land use level [25]. Moreover, an interesting finding was that the mean LST value of residential land use in the outer suburb $\left(36.75^{\circ} \mathrm{C}\right)$ was higher than that of the city suburbs $\left(35.67^{\circ} \mathrm{C}\right)$, which was neither significantly different from that in the inner city $\left(37.06^{\circ} \mathrm{C}\right)$ nor central city $\left(36.87^{\circ} \mathrm{C}\right)$, while the percentage of vegetated land cover was the largest, and the percentage of building land cover was lowest in the residential land use of outer suburbs (Fig. 6). For this contradictory finding, a field survey was conducted in these residential land use samples. It was found that most vegetated land in the residential land use samples of the outer suburb was mainly covered by vegetation with open structures and immature trees (Fig. 7) due to limited growth time or design style. Furthermore, many studies have confirmed that vegetated land with proper vegetation densities and thick-leaved trees could greatly influence the thermal environment [48, 49]. Thus, the cooling effect of the vegetated land in residential land use samples of the outer suburbs was relatively limited. This finding further confirmed that LST distribution was not only affected by land cover patterns, but that the features of land cover such as the vegetated land could also play an important role in affecting the thermal environment [27, 48].

It was shown in Tables 6 and 7 that the land cover variables related to LST values in residential land use varied greatly along the urbanization gradients.
Most land cover variables were related to the LST of residential land use in the inner city. And the PLAND of vegetated land had the strongest relationship with LST values of these land use polygons, where the percentage cover of vegetated land was lowest compared to the other land use polygons located in central city, city suburb and outer suburb (Fig. 6). This finding implied that the smaller the percentage cover of vegetated land in one given land use polygon, the more sensitive it was to LST [18, 24]. Xie et al. (2013) found that in highly vegetated areas, increasing vegetated land cover can reduce temperature, but the effect will be insignificant [18]. On the other hand, the LST of residential land use in the outer suburb was only significantly correlated to the PLAND of building land cover and the MPS of vegetated land cover. Moreover, the regression models in Table 7 showed that increases in the MNN of building land could reduce the LST of residential land use in the central city and city suburb. While decreases in the PLAND of building land could reduce the LST of residential land use in the city suburb and outer suburb. All of the above findings further suggested the complicated relationship of LST with land cover patterns even under a given level of anthropogenic activities. For one given land use type, the relations of LST with land cover variables could be quite different due to the various land cover compositions and features in each land use polygon [24, 25].

\section{Implications for Urban Planning and Some Limitations}

Urbanization has increased spatial complexity by changing land cover patterns in different land use types and fragmentation of natural land [50]. Many studies have been conducted to find the changes in spatial structure and their impacts on urban thermal environments [51, 52]. Even though land cover has been confirmed as one main factor affecting LST, it was found in this study that the relationships of LST with land cover are quite different in various land 
Table 6. Partial correlation between LST and land cover in residential land use along urbanization gradients.

\begin{tabular}{|c|c|c|c|c|}
\hline & Inner city & Central city & City suburb & Outer suburb \\
\hline \multicolumn{5}{|c|}{ Vegetated land cover } \\
\hline $\begin{array}{l}\text { Percentage of land cover } \\
\text { (PLAND) }\end{array}$ & $-0.918 * *$ & $-0.668^{* *}$ & & \\
\hline Patch density (PD) & $-0.854 * *$ & & & \\
\hline Mean patch size (MPS) & $-0.620 * *$ & $-0.480 *$ & & $-0.552 *$ \\
\hline Mean proximity index (MPI) & & $-0.474 *$ & & \\
\hline Mean nearest neighbor (MNN) & & & $-0.521^{*}$ & \\
\hline Patch size coefficient of variance (PSCoV) & $-0.759 * *$ & & & \\
\hline \multicolumn{5}{|l|}{ Mean shape index (MSI) } \\
\hline \multicolumn{5}{|c|}{ Building land cover } \\
\hline Percentage of land cover (PLAND) & $0.884 * *$ & $0.730 * *$ & $0.650 * *$ & $0.579 *$ \\
\hline Patch density (PD) & $0.755^{* *}$ & $0.560 * *$ & & \\
\hline Mean patch size (MPS) & & $-0.472 *$ & & \\
\hline Mean proximity index (MPI) & $0.755^{* *}$ & & & \\
\hline Mean nearest neighbor (MNN) & $-0.832 * *$ & & $-0.658^{*}$ & \\
\hline Patch size coefficient of variance (PSCoV) & & & $0.592 *$ & \\
\hline Mean shape index (MSI) & $0.510^{*}$ & & & \\
\hline \multicolumn{5}{|c|}{ Roads and squares } \\
\hline Percentage of land cover (PLAND) & & & $-0.632 *$ & \\
\hline Patch density (PD) & & $-0.427 *$ & & \\
\hline Mean patch size (MPS) & & $0.446^{*}$ & & \\
\hline \multicolumn{5}{|l|}{ Mean proximity index (MPI) } \\
\hline \multicolumn{5}{|l|}{ Mean nearest neighbor (MNN) } \\
\hline \multicolumn{5}{|l|}{ Patch size coefficient of variance (PSCoV) } \\
\hline Mean shape index (MSI) & & & & \\
\hline
\end{tabular}

* Correlation was significant at the level of 0.05 (two-tailed)

** Correlation was significant at the level of 0.01 (two-tailed)

Table 7. Results from the regression models for the LST in residential land use.

\begin{tabular}{|c|c|c|c|c|c|c|}
\hline Location & Model & Variables & Coefficient & $\begin{array}{c}\text { Stand. } \\
\text { Coeff. }\end{array}$ & Model R2 & Adjusted R2 \\
\hline Inner city & 5 & $\begin{array}{c}\text { Veg_PLAND } \\
\text { Veg_PD }\end{array}$ & $\begin{array}{c}-3.327^{* *} \\
-0.040^{* *}\end{array}$ & $\begin{array}{c}-0.632 \\
-0.383\end{array}$ & 0.908 & 0.895 \\
\hline Central city & 6 & Build_MNN & $-0.083^{* *}$ & -0.790 & 0.624 & 0.606 \\
\hline City suburb & 7 & $\begin{array}{c}\text { Build_PLAND } \\
\text { Build_MNN }\end{array}$ & $\begin{array}{c}3.718^{* *} \\
-0.043^{* *}\end{array}$ & $\begin{array}{c}0.589 \\
-0.489\end{array}$ & 0.752 & 0.706 \\
\hline Outer suburb & 8 & Build_PLAND & $3.533^{*}$ & 0.579 & 0.336 & 0.280 \\
\hline
\end{tabular}

Build_PLAND and Veg_PLAND refer to the percentage of building land cover, vegetated land cover, respectively. Build_MNN refers to the mean nearest neighbor of building land cover. Veg_PD refers to the patch density of vegetated land cover.

* Correlation was significant at the level of 0.05 (two-tailed)

** Correlation was significant at the level of 0.01 (two-tailed) 
use types, and even for the same land use type with different land cover compositions [24, 25]. Our study revealed that we could regulate the LST distribution by altering the land cover patterns in various land use types and even for the same land use type according to their composition features. For instance, the PD of vegetated land was negatively related to the LST of residential and industrial land use. In contrast, the LST was positively related to the PD of vegetated land in park land use. This finding indicates that an open space system, composed by interconnected vegetated lands spread within the considered land use categories, would be able to better mitigate the LST values in comparison to greater and isolated vegetated lands. And this finding was consistent with the relusts of one previous study in Nanjing, China [33]. For the building land cover, MNN and MPS were both negatively related to the LST of residential land use. This finding suggests that a dispersed pattern of larger building land may better regulate the LST in residential land use. Moreover, the MPS of building land was found to be positively related to the LST of industrial and institutional land use. This finding indicates that the extent of building land in these land use types should be limited to better mitigate LST. Overall, it appeared in this study that landscapes with properly higher centralized building land and interspersing vegetated land may contribute to lower micro-scale LST in residential land use and possibly in industrial land use. This finding was consistent with the studies by Li et al. [19] and Connors et al. [26].

However, there are still some drawbacks and limitations in this study that should be further explored. First, it was found in this study that anthropogenic activities in various land use types may also play an important role in affecting the LST. Thus, future studies should be conducted for quantifying and distinguishing the contributions of biophysical and anthropogenic forces to LST. Second, this study was designed to focus on finding the relationships of LST with land cover patterns in various land use types along urbanization gradients at the horizontal scale. The special features of various land cover such as building height $[28,46]$, vegetated land structure [48] etc., which may also affect the LST distribution,were not seriously considered in our study. Lastly, it was found in this study that the relations of LST with land cover variables in various land use types were quite significant, and that these variables differed greatly among the selected land use types, possibly due to their complicated composition features. In view oft his finding, future studies should expand this research with consideration of more land use polygons so as to find out the inflection points between LST and land cover in each land use type.

\section{Conclusions}

By distinguishing the difference between land use and land cover, this study comprehensively analyzed the relationships of LST with land cover in various land use types alongurbanization gradients in the southwest region of Shanghai. It was revealed that land cover should not be considered as the single factor affecting LST distribution. Anthropogenic factors and land cover features may also play an important role in affecting the LST distribution. Even though land cover variables were found to be significantly related to LST, it was also clear that the variables affecting LST vary greatly among the various land use types at a fine scale. Land cover compositions had stronger correlations with LST than land cover configurations. Building land was associated with high LST, while vegetated land was related to low LST. Moreover, for the various land use types, land cover variables related to LST were quite different due to their complicated compositions and anthropogenic activities. Based on the findings in this study, different strategies for optimizing the land cover patterns with the aim to mitigate the urban thermal environment should be proposed according to the complicated land use contexts. For instance, a dispersed pattern of larger building land may better regulate the LST in residential land use, while the extent of building land should be limited to better mitigate the LST in industrial and institutional land use. All the findings in our study could provide important implications for urban land planning and management to mitigate the adverse impacts of UHIs at fine scale.

\section{Acknowledgements}

The authors are grateful for financial support from the Projects of the National Natural Science Foundation of China (31470702). We also thank Dr. Sijia Jin of Shanghai Jiao Tong University and Dr. Qingwei Wang of Tohoku University for their professional advice regarding the manuscript.

\section{Conflict of Interest}

The authors declare no conflict of interest.

\section{Abbreviations}

$\begin{array}{ll}\text { LST } & \text { Land Surface Temperature } \\ \text { LULC } & \text { Land Use/Land Cover } \\ \text { UHI } & \text { Urban Heat Island } \\ \text { PLAND } & \text { Percentage of Land Cover } \\ \text { PD } & \text { Patch Density } \\ \text { MPS } & \text { Mean Patch Size } \\ \text { MPI } & \text { Mean Proximity Index } \\ \text { MNN } & \text { Mean Nearest Neighbor } \\ \text { PSCoV } & \text { Patch Size Coefficient of Variance } \\ \text { MSI } & \text { Mean Shape Index }\end{array}$




\section{References}

1. CHEN H., CHEN G.Q., JI X. Cosmic emergy based ecological systems modelling. Communications in Nonlinear Science \& Numerical Simulation, 15 (9), 2672, 2010.

2. MONDAL P., SOUTHWORTH J. Evaluation of conservation interventions using a cellular automatamarkov model. Forest Ecology \& Management, 260 (10), 1716, 2010.

3. ANGEL S., PARENT J., CIVCO D.L., BLEI A., POTERE D. The dimensions of global urban expansion: Estimates and projections for all countries, 2000-2050. Progress in Planning, 75 (2), 53, 2011

4. DEWAN A.M., CORNER R.J. The impact of land use and land cover changes on land surface temperature in a rapidly urbanizing megacity. Geoscience and Remote Sensing Symposium, IEEE, 6337, 2012.

5. LI J., SONG C., CAO L., ZHU F., MENG X., WU J. Impacts of landscape structure on surface urban heat islands: A case study of Shanghai, China. Remote Sensing of Environment, 115 (12), 3249, 2011.

6. WIEDMANN T.O., SCHANDL H., LENZEN M., MORAN D., SUH, S., WEST J., KANEMOTO K. The material footprint of nations. Proceedings of the National Academy of Sciences of the United States of America, 112 (20), 6271, 2015

7. EROL A., EKINCI K., AKBOLAT D., EVRENDILEK F. Modeling impacts of land uses on carbon and nitrogen contents, carbon dioxide and water effluxes of Mediterranean soils. Polish Journal of Environmental Studies, 25 (4), 2016.

8. SONG Y., WU C. Examining the impact of urban biophysical composition and neighboring environment on surface urban heat island effect. Advances in Space Research, 57 (1), 96, 2016.

9. HAMOODI M.N., CORNER R., DEWAN A. Thermophysical behaviour of lulc surfaces and their effect on the urban thermal environment. Spatial Science, 1, 1, 2017.

10. MUSHORE T.D., MUTANGA O., ODINDI J., DUBE T. Determining extreme heat vulnerability of Harare Metropolitan City using multispectral remote sensing and socio-economic data. Journal of Spatial Information Science, 63 (1), 173, 2017.

11. KALNAY E., CAI M. Impact of urbanization and land-use change on climate. Nature, 423 (6939), 528, 2003.

12. IMHOFF M.L., ZHANG P., WOLFE R.E., BOUNOUA L. Remote sensing of the urban heat island effect across biomes in the continental USA. Remote Sensing of Environment, 114 (3), 504-513, 2010.

13. HUANG Q., LU Y. The effect of urban heat island on climate warming in the Yangtze River Delta urban agglomeration in China. International Journal of Environmental Research \& Public Health, 12 (8), 8773, 2015.

14. HUMPHREYS M. Outdoor temperatures and comfort indoors. Batiment International/Building Research \& Practice, 6 (2), 92, 1978.

15. PATZ J.A., CAMPBELLLENDRUM D., HOLLOWAY T., FOLEY J.A. Impact of regional climate change on human health. Nature, 438 (7066), 310, 2005.

16. LAHARIYA C. The state of the world population 2007: Unleashing the potential of urban growth. Indian Pediatrics, 45 (6), 481, 2008.
17. United Nations. Department of Economic and Social Affairs. World urbanization prospects: The 2007 revision. Highlights. New York, New York, United Nations, 22 (8), 656, 2008.

18. XIE M., WANG Y., CHANG Q., FU M., YE M. Assessment of landscape patterns affecting land surface temperature in different biophysical gradients in Shenzhen, China. Urban Ecosystems, 16 (4), 871, 2013.

19. LI W., BAI Y., CHEN Q., HE K., JI X., HAN C. Discrepant impacts of land use and land cover on urban heat islands: A case study of Shanghai, China. Ecological Indicators, 47, 171, 2014

20. WENG Q. Thermal infrared remote sensing for urban climate and environmental studies: Methods, applications, and trends. Isprs Journal of Photogrammetry \& Remote Sensing, 64 (4), 335, 2009.

21. NICHOL J.E., FUNG W.Y., LAM K.S., MAN S.W. Urban heat island diagnosis using ASTERsatellite images and 'in situ' air temperature. Atmospheric Research, 94 (2), 276, 2009.

22. XIAN G.C., M. An analysis of urban thermal characteristics and associated land cover in Tampa Bay and Las Vegas using Landsat satellite data. Remote Sensing of Environment, 104 (2), 147, 2006.

23. LIANG B., WENG Q. Multiscale analysis of census-based land surface temperature variations and determinants in Indianapolis, United States. Journal of Urban Planning \& Development, 134 (3), 129-, 2008.

24. HAN M.Y., SHAO L., LI J.S., GUO S., MENG J., AHMAD B., HAYAT T., ALSAADI F., JI X., ALSAEDI A. Emergybased hybrid evaluation for commercial construction engineering: A case study in BDA. Ecological Indicators, 47, 179, 2014

25. BUYANTUYEV A., WU J. Urban heat islands and landscape heterogeneity: Linking spatiotemporal variations in surface temperatures to land-cover and socioeconomic patterns. Landscape Ecology, 25 (1), 17, 2010.

26. CONNORS J.P., GALLETTI C.S., CHOW W.T.L. Landscape configuration and urban heat island effects: Assessing the relationship between landscape characteristics and land surface temperature in Phoenix, Arizona. Landscape Ecology, 28 (2), 271, 2013.

27. LI X., ZHOU W., OUYANG Z. Relationship between land surface temperature and spatial pattern of greenspace: What are the effects of spatial resolution? Landscape \& Urban Planning, 114 (8), 1, 2013.

28. YAN H., FAN S., GUO C., HU J., DONG L. Quantifying the impact of land cover composition on intra-urban air temperature variations at a mid-latitude city. Plos one, 9 (7), e102124, 2014

29. ZHOU W., HUANG G., CADENASSO M.L. Does spatial configuration matter? Understanding the effects of land cover pattern on land surface temperature in urban landscapes. Landscape \& Urban Planning, 102 (1), 54, 2011.

30. LUCK M., WU J. A gradient analysis of urban landscape pattern: A case study from the Phoenix metropolitan region, Arizona, USA. Landscape Ecology, 17 (4), 327, 2002.

31. TURNER M.G. Landscape ecology: What is the state of the science? Annual Review of Ecology Evolution \& Systematics, 36 (36), 319, 2005.

32. MAIMAITIYIMING M.G., A., TIYIP T., PLA F., LATORRE-CARMONA P., HALIK Ü., SAWUT M., CAETANO M. Effects of green space spatial pattern on land surface temperature: Implications for sustainable 
urban planning and climate change adaptation. ISPRS Journal of Photogrammetry and Remote Sensing, 89, 59, 2014.

33. ZHANG X.Y. ZHONG T.Y., FENG, X.Z., KE W. Estimation of the relationship between vegetation patches and urban land surface temperature with remote sensing. International Journal of Remote Sensing, 30 (8), 2105, 2009.

34. RAHMAN A.M.D.Y.Y.M.Z. Dynamics of land use/cover changes and the analysis of landscape fragmentation in DhakaMetropolitan, Bangladesh. GeoJournal, 77 (3), 315, 2012.

35. ZHOU Y., WENG Q., GURNEY K.R., SHUAI Y., HU X. Estimation of the relationship between remotely sensed anthropogenic heat discharge and building energy use. Isprs Journal of Photogrammetry \& Remote Sensing, 67 (3), 65, 2012.

36. SMITH C., LINDLEY S., LEVERMORE G. Estimating spatial and temporal patterns of urban anthropogenic heat fluxes for UK cities: The case of Manchester. Theoretical \& Applied Climatology, 98 (1-2), 19, 2009.

37. SAILOR D.J. A review of methods for estimating anthropogenic heat and moisture emissions in the urban environment. International Journal of Climatology, 31 (2), 189, 2011.

38. ZHANG D.L., SHOU Y.X., DICKERSON R.R., CHEN F. Impact of upstream urbanization on the urban heat island effects along the Washington-Baltimore Corridor. Journal of Applied Meteorology \& Climatology, 50 (10), 2012, 2011.

39. SHEN X. Urban sprawl and dynamic simulation of Shanghai. East China Normal University, 2010 [In Chinese]

40. RIDD M.K. Exploring a V-I-S (vegetation-impervious surface-soil) model for urban ecosystem analysis through remote sensing: Comparative anatomy for citiesâ. International Journal of Remote Sensing,16 (12), 2165, 1995.

41. JIMÉNEZ-MUÑOZ J.C., SOBRINO J.A. A generalized single-channel method for retrieving land surface temperature from remote sensing data. Journal of Geophysical Research Atmospheres, 108 (D22), 2003.

42. VALOR E., CASELLES V. Mapping land surface emissivity from NDVI: Application to European, African, and South American areas. Remote Sensing of Environment, 57 (3), 167, 1996.
43. SOBRINO J.A., JIMÉNEZ-MUÑOZ J.C., PAOLINI L. Land surface temperature retrieval from LANDSAT TM 5. Remote Sensing of Environment, 90 (4), 434, 2004.

44. MCGARIGAL K. Fragstats : Spatial pattern analysis program for categorical maps. Computer software program produced by the authors at the university of Massachusetts, Amherst.Www.umass.edu/landeco/research/fragstats/ fragstats.html 2002.

45. LIN P., GOU Z., LAU S.Y., QIN, H. The impact of urban design descriptors on outdoor thermal environment: A literature review. Energies, 10 (10), 2151, 2017.

46. LIU W., FEDDEMA J., HU L., ZUNG A., BRUNSELL N. Seasonal and diurnal characteristics of land surface temperature and major explanatory factors in Harris county, Texas. Sustainability, 9 (12), $2324,2017$.

47. ARNFIELD A.J. Two decades of urban climate research: A review of turbulence, exchanges of energy and water, and the urban heat island. International Journal of Climatology, 23 (1), 1, 2003.

48. QIN Z., LI Z., CHENG F., CHEN J., LIANG B. Influence of canopy structural characteristics on cooling and humidifying effects of Populus tomentosa community on calm sunny summer days. Landscape \& Urban Planning, 127, 75, 2014.

49. SHAHIDAN M.F., SHARIFF M.K., JONES P., SALLEH E., ABDULlAH A.M. A comparison of Mesua ferrea L. and Hura crepitans L. for shade creation and radiation modification in improving thermal comfort. Landscape \& Urban Planning, 97 (3), 168, 2010.

50. WU J., JENERETTE G.D., BUYANTUYEV A., REDMAN C.L. Quantifying spatiotemporal patterns of urbanization: The case of the two fastest growing metropolitan regions in the United States. Ecological Complexity, 8 (1), 1, 2011.

51. KOTTMEIER C., BIEGERT C., CORSMEIER U. Effects of urban land use on surface temperature in Berlin: Case study. Journal of Urban Planning \& Development, 133 (2), 128, 2007.

52. KOTHARKAR R., SURAWAR M. Land use, land cover, and population density impact on the formation of canopy urban heat islands through traverse survey in the Nagpur urban area, India. Journal of Urban Planning \& Development, 142 (1), 04015003, 2016. 